\title{
Surgical Technique for Aneurysms at the A3 Segment of Anterior Cerebral Artery Via Anterior Interhemispheric Keyhole Approach
}

\author{
Shu-Fa ZHENG ${ }^{*}$, Pei-Sen $Y_{A O}{ }^{*}$, Liang-Hong YU ${ }^{1}$, De-Zhi KANG ${ }^{1,2}$ \\ ${ }^{1}$ The First Affiliated Hospital of Fujian Medical University, Department of Neurosurgery, China \\ ${ }^{2}$ The First Affiliated Hospital of Fujian Medical University, Institute of Neurology, China \\ *Shu-Fa ZHENG and Pei-Sen YAO equally contributed to this article.
}

\section{ABSTRACT}

\begin{abstract}
AIM: Traditional craniotomies for treatment of the aneurysms at the A3 segment of anterior cerebral artery (A3As), such as frontal approach and interhemispheric approach, require pre-hairline incision and relatively long incision, extensive bone flap, inevitable supraorbital nerve injury, opening frontal sinus, and increased operative time. Here we reported anterior interhemispheric keyhole approach with minimally invasive advantages for treatment of A3As.
\end{abstract}

MATERIAL and METHODS: Thirteen A3As and one A1 aneurysm in thirteen patients were confirmed by computed tomographic angiography (CTA) and/or digital subtraction angiography (DSA). All patients underwent anterior interhemispheric keyhole approach with a hairline incision across the midline and a bone flap 3-4 cm in diameter, combined with external ventricular drainage, neuronavigation, intraoperative neurophysiological monitoring (IONM), and transcranial Doppler (TCD). Clinical characteristics and therapeutic results of the patients were analyzed, and the postoperative functional capacities of those patients were evaluated using Glasgow Outcome Scale (GOS) six months later.

RESULTS: All aneurysms were successfully obliterated via the anterior interhemispheric keyhole approach combined with external ventricular drainage. Mean duration of surgery (from skin incision to wound closure) was 100 minutes with a range of 70 to 135 minutes. No severe interhemispheric keyhole approach related complications, postoperative infections, secondary intracranial haemorrhage, severe cerebral vasospasm, and aneurysmal neck remnants were detected. Median hospital stay after surgery was 9.0 days (range 8 to 11 days). And the postoperative functional capacities evaluated by GOS were normal six months later.

CONCLUSION: The anterior interhemispheric keyhole approach combined with external ventricular drainage is a safe, effective, and minimally invasive craniotomy technique for the treatment of A3 aneurysms.

KEYWORDS: Interhemispheric approach, Keyhole approach, Aneurysm, Anterior cerebral artery

\section{INTRODUCTION}

A neurysms at the $\mathrm{A} 3$ segment of anterior cerebral artery (ACA) constitute $2 \%$ to $7 \%$ of all intracranial aneurysms and surgical management presents some unique technical difficulties $(3,6,11,13,20,23,28,30,32,35,36,39,41,46,48$,
49,51). The aneurysms at the A3 segment of anterior cerebral artery (A3As) are usually small and difficult to be exposed because of their deep site in the interhemispheric fissure and specific orientation of the pericallosal artery. As A3As are rare, it is difficult to obtain experience in microneurosurgical treatment $(19,27,31,33,34,51)$. Nevertheless, aneurysm clipping is 
shown to be a sustained and effective management for the A3As (24).

Traditional approaches for A3As clipping such as frontal, bifrontal, frontotemporal, and frontolateral craniotomies have been acknowledged and extensively applied. It is no doubt that aneurysm clipping at the A3 segment of ACA can be performed successfully via traditional interhemispheric craniotomy $(3-5,15,24,25,42,50)$. However, there exists a relatively long bicoronal, semi (unilateral)-coronal or horseshoe-shaped incision, a relatively extensive bone and brain exposure in the traditional craniotomy for the treatment of A3As, which is time-consuming and iatrogenic traumatizing not related to the aneurysms themselves. Although Fukushima et al. reported that the interhemispheric approach with the incision on the forehead wrinkle, which was the shortest path to the lesion, had been applied to the ACA aneurysm clipping successfully (8). In addition to the postoperative scar on the forehead, it was inevitable that the patients would feel forehead numbness postoperatively because of cutting off the supraorbital nerve, and opening frontal sinus would increase the risk of infection during surgery (44). Limited exposure in cerebral surgery is the goal that neurosurgeons constantly pursue in the $21^{\text {st }}$ century (47). Along with the improvement of the preoperative diagnostic tools, intraoperative illumination devices and neurosurgical instruments, the neurosurgical interventions are less dangerous and less invasive. And the keyhole approach in neurosurgery has evolved gradually from traditional craniotomy. Therefore, the anterior interhemispheric keyhole approach with a hairline incision across the midline and a bone flap 3-4 cm in diameter is introduced to overcome the above drawbacks. And it is exactly true that the keyhole approach combined with the assistive technologies, such as neuronavigation $(17,18)$, and intraoperative neurophysiological monitoring $(9,45)$, are recommended for overcoming the technical challenges of A3As $(7,8,10,21,22,26,40)$. Here, we report our preliminary experience in the management of $A 3 A$ s via anterior interhemispheric keyhole approach.

\section{MATERIAL and METHODS}

\section{Patient Population}

Thirteen patients (seven males and six females, aged 15-67 years) manifesting as spontaneous subarachnoid hemorrhage $(\mathrm{SAH})$, associated with varying degrees of interhemispheric hematoma, were admitted to hospital, diagnosed by computed tomography angiography (CTA) and/or digital subtraction angiography (DSA), and underwent anterior interhemispheric keyhole approach between January 2005 and September 2014.

Clinical datas of the 13 patients are presented in Table I, II. All 13 patients are right-handed and underwent preoperative and postoperative CTA and/or DSA evaluations. 3D-CTA (three-dimensional CTA) or 3D-DSA (three-dimensional DSA) was performed to obtain more detailed information about the orientation and morphology of the aneurysms. Angiography demonstrated that there were thirteen aneurysms located at A3 segment (three superior A3As, six anterior A3As, and four inferior A3As) and one aneurysm located at $A 1$ segment (A1A). All of the 14 aneurysms were saccular aneurysms, and the

Table I: Clinical Characteristics of the Patients

\begin{tabular}{|c|c|c|c|c|c|c|c|}
\hline Patient & $\begin{array}{l}\text { Age } \\
\text { (yrs) }\end{array}$ & Sex & $\begin{array}{c}\text { Aneurysm } \\
\text { morphology }\end{array}$ & Site of aneurysm & $\begin{array}{c}\text { Diameter of } \\
\text { aneurysm (mm) }\end{array}$ & $\begin{array}{c}\text { Hunt-Hess } \\
\text { Scale }\end{array}$ & $\begin{array}{l}\text { Postoperative } \\
\text { complications }\end{array}$ \\
\hline 1 & 15 & $\mathrm{M}$ & NN, Sac & Right, superior A3 & 5.0 & 1 & none \\
\hline 2 & 35 & $\mathrm{~F}$ & NN, Sac & Right, superior A3 & 4.0 & 1 & none \\
\hline 3 & 43 & M & NN, Sac & Right, anterior $\mathrm{A} 3$ & 3.0 & II & none \\
\hline 4 & 51 & $\mathrm{~F}$ & NN, Sac & Left, anterior $\mathrm{A} 3$ & 3.0 & II & none \\
\hline 5 & 36 & $\mathrm{~F}$ & NN, Sac & Left, inferior A3 & 3.5 & I & none \\
\hline 6 & 39 & M & NN, Sac & Right, superior A3 & 3.0 & 1 & none \\
\hline 7 & 27 & M & NN, Sac & Right, inferior A3 & 2.0 & I & none \\
\hline 8 & 40 & $\mathrm{~F}$ & NN, Sac & Right, anterior $\mathrm{A} 3$ & 3.0 & II & none \\
\hline 9 & 31 & $M$ & NN, Sac & Left, anterior $\mathrm{A} 3$ & 2.5 & II & none \\
\hline 10 & 46 & $\mathrm{~F}$ & NN, Sac & Left, inferior A3 & 3.0 & II & none \\
\hline 11 & 48 & M & NN, Sac & Right, anterior $\mathrm{A} 3$ & 2.5 & II & none \\
\hline 12 & 60 & M & NN, Sac & Left, inferior A3 & 3.0 & II & none \\
\hline 13 & 67 & $\mathrm{~F}$ & NN, Sac & $\begin{array}{l}\text { Left, anterior } A 3 \text { and } A 1 \\
\text { segment of } A C A\end{array}$ & $\begin{array}{c}3.0 \text { (anterior } \mathrm{A} 3) \\
2.0(\mathrm{~A} 1)\end{array}$ & II & none \\
\hline
\end{tabular}

M: Male, F: Female, yrs: Years, NN: Narrow-necked, Sac: Saccular, A3: A3 segment of ACA, A4: A4 segment of ACA. 
median diameter of the aneurysm was $3.6 \mathrm{~mm}$ (range 2.0 to $5.0 \mathrm{~mm}$ ). The patient's preoperative conditions were assessed according to Hunt-Hess Scale (eight with Hunt Hess grade II, and five with grade I). All 13 patients underwent anterior interhemispheric keyhole approach within 3 days after hemorrhage. All patients were treated with the traditional postoperative management of aneurysmal SAH. The clinical

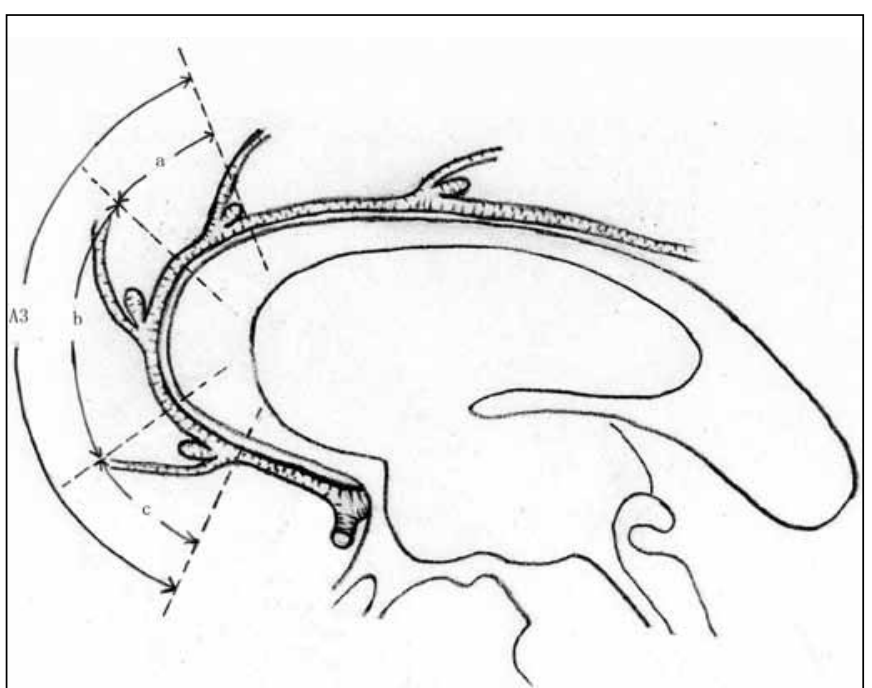

Figure 1: Microneurosurgical division of the aneurysm on the $A 3$ segment of ACA according to its relative position of the corpus callosum. a, represented superior $A 3 ; \mathbf{b}$, represented anterior $A 3$; c, represented inferior A3. characteristics and therapeutic results of the patients were analyzed, such as aneurysm location, operative time, and hospital stay. All patients had clinical and radiological followup with CT or CTA. The postoperative functional capacities of those patients were evaluated by Glasgow Outcome Scale (GOS) six months later.

\section{Operative Technique}

Under general anesthesia, the patient was placed in the supine position with head tilted about 30 degrees superiorly, without rotation or lateral tilting. And the patients underwent somatosensory evoked potential (SEP) and/or motor evoked potential (MEP) monitoring in our A3As surgeries for detecting cerebral ischemia changes, which is induced by temporary occlusion of the parent artery. Regardless of the locations of the aneurysms in these thirteen patients, the right-sided anterior interhemispheric keyhole approach was chosen to avoid iatrogenic traumatizing to dominant hemisphere, and it is also convenient for a right-handed neurosurgeon. As the flow of cerebrospinal fluid (CSF) may be obstructed by subarachnoid clot after aneurysmal subarachnoid hemorrhage, and the CSF cannot be easily removed from the interhemispheric fissure, consequently, contralateral external ventricular drainage was performed, which was partly combined with intracranial pressure device (ICP), preferably on the right side. The burrhole was made $1 \mathrm{~cm}$ anterior to the coronal suture and 2.5 $\mathrm{cm}$ lateral to the midline. And the catheter was placed in the anterior horn of the lateral ventricle and tunneled under the scalp. The distal end of the catheter was inserted about 5-6 $\mathrm{cm}$ until CSF was well obtained. The catheter was sutured to the skin, and connected to an external drainage system for

Table II: Clinical Results of 13 Patients Submitted to Surgery

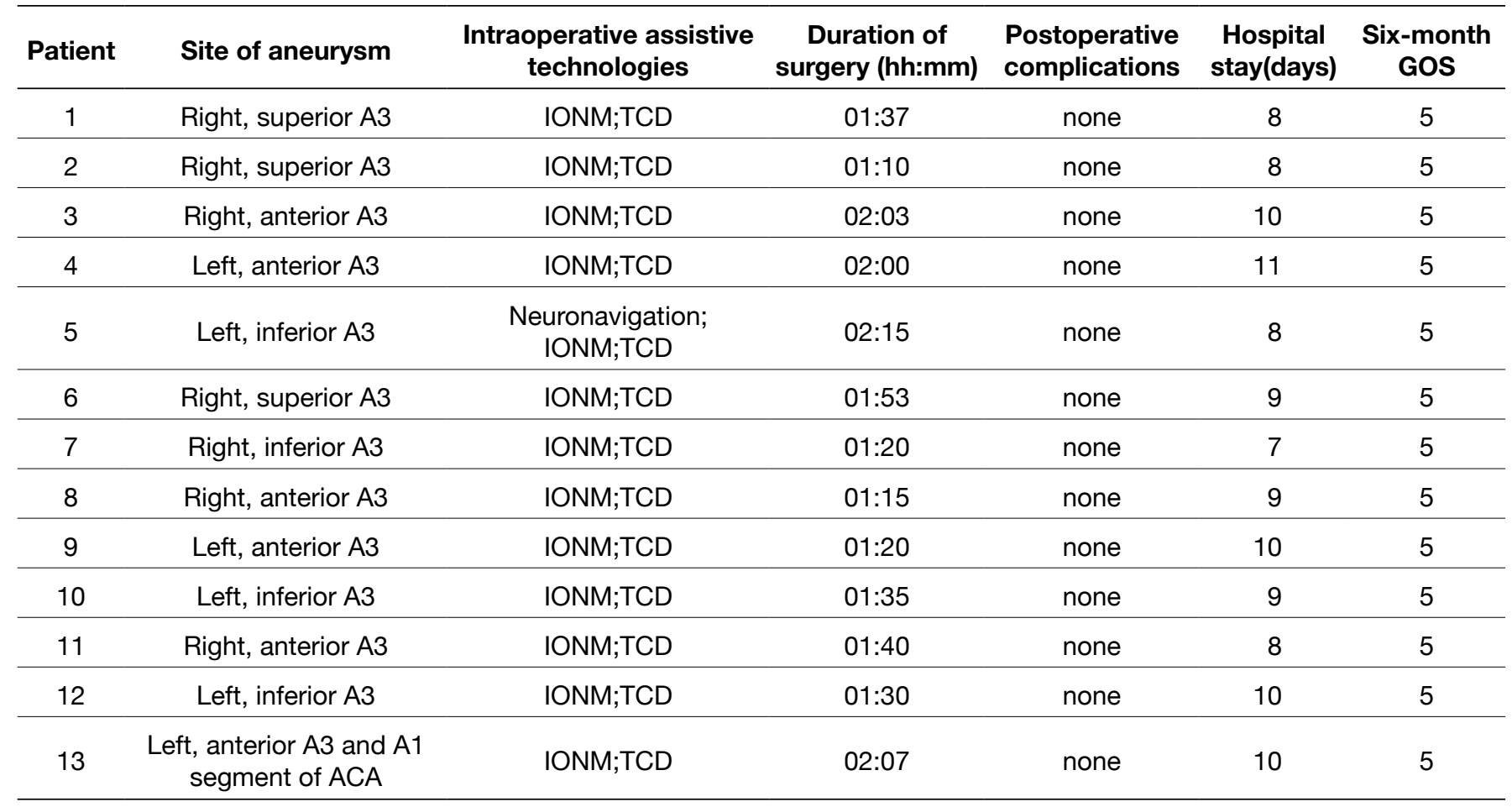

GOS: Glasgow Outcome Scale, IONM: Intraoperative neurophysiological monitoring, TCD: Transcranial Doppler. 
draining ventricular CSF. Then a 7-cm right-side asymmetric hairline incision across the midline was place on the forehead, which could prevent scarring on the forehead outside the hairline (Figures 2, 3). After the scalp being incised, a burr hole was drilled in the midline just above the superior sagittal sinus (SSS). Then, the holes were enlarged with rongeur. It is recommended that gelatin sponge may be filled between the bone and the SSS through the enlarged holes, and the injury to the SSS can be avoided during milling the bone, then a bone flap 3-4 cm in diameter is made (Figure 2). After the dura on the right side was opened with a " $\mathrm{C}$ " incision, it was found that the bridging veins draining into the superior sagittal sinus were rarely encountered in these patients. In addition, in most cases the bridging veins were small and their sacrifice was well tolerated $(41,42)$. After CSF was removed from the ventricular system slowly and brain relaxation occured, enough working space was provided for clipping aneurysms. Then the frontal lobe should be dissected and retracted carefully and minimally to avoid intraoperative premature rupture of the aneurysms and iatrogenic traumatizing to frontal lobe. Meanwhile, the superficial bridging vein should also be carefully protected. The interhemispheric fissure was subsequently exposed (Figure $5 \mathrm{~A})$. And then the callosomarginal artery and pericallosal artery were unveiled, and the genu of the corpus callosum was approached and could be used as an anatomical landmark for orientation. Finally, the A3As and the proximal segment of parent artery were visible (Figures 5B-F). If the A3As are difficult to locate intraoperatively, the neuronavigation can be prepared for finding the correct angle and approach to the aneurysm (Case 5). After identifying of the parent artery and the branches, the aneurysmal neck was dissected completely and defined accurately. Before the final clipping was made with particular care to obliterate the aneurysmal neck completely, all vascular anatomy should be confirmed. In addition, the temporary occlusion of parent artery was carried out when clipping aneurysmal neck which should be separated successfully and rapidly to avoid cerebral ischemic events and Transcranial Doppler (TCD) was applied to detect vascular stenosis during the surgeries. After completion of the intracranial procedure, the dura was closed with watertight sutures and the bone flap was fixed. Then the galea and scalp were sutured.

\section{RESULTS}

Clinical results of the 13 patients are presented in Table II. After being fully prepared for surgery, all 13 patients here were treated by the right anterior interhemispheric keyhole approach, which was selected as the optimal surgical planning to avoid iatrogenic traumatizing to dominant hemisphere. It was lucky that no bridging veins were encountered in our cases. After drainage of the CSF from ventricular system, enough operative space was obtained for clipping A3As because of satisfactory relaxation of the genu of corpus callosum and the frontal lobe, even the A1 segment of ACA. And adjustment of microscope makes the A3As (including the inferior A3As) and the proximal end of the parent artery be exposed more easily during aneurysm clipping (Figure 3 , line B), which could facilitate surgeon to obtain desired

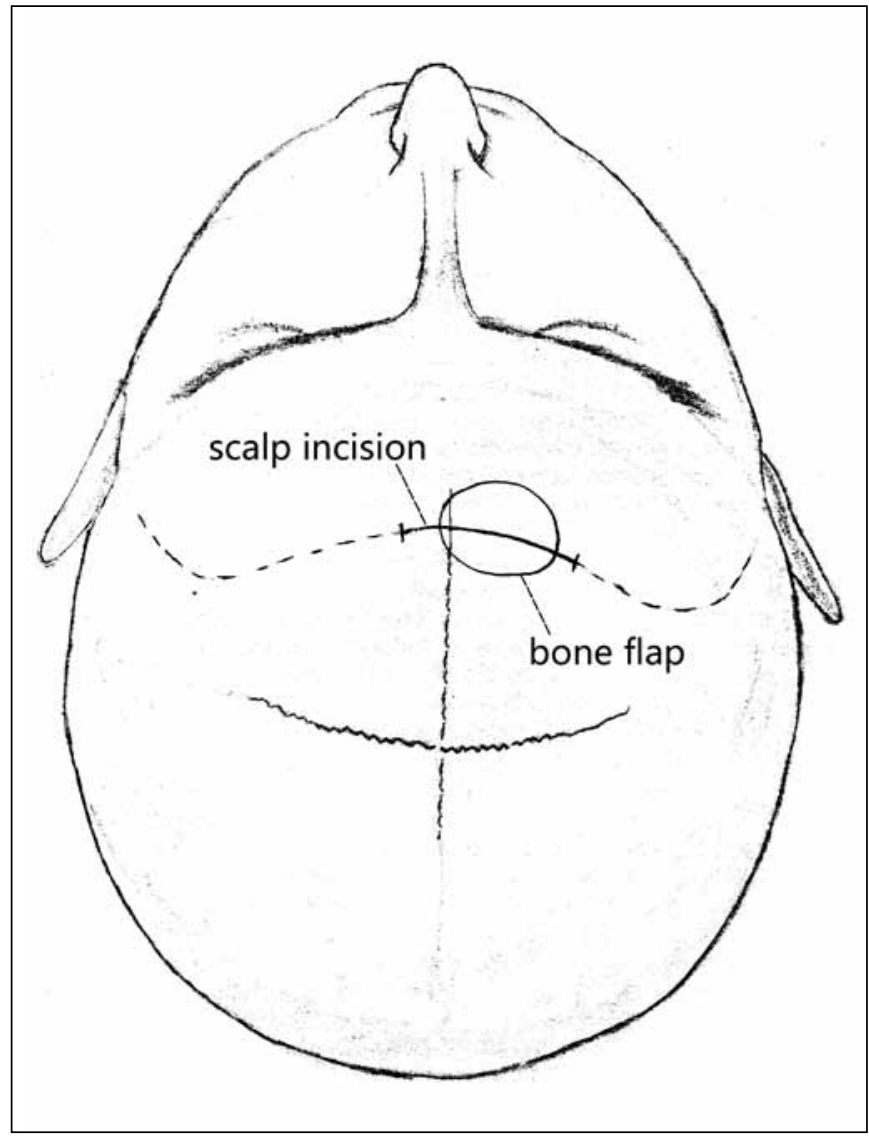

Figure 2: Illustration demonstrating the location of the bone flap for treatment of A3As.

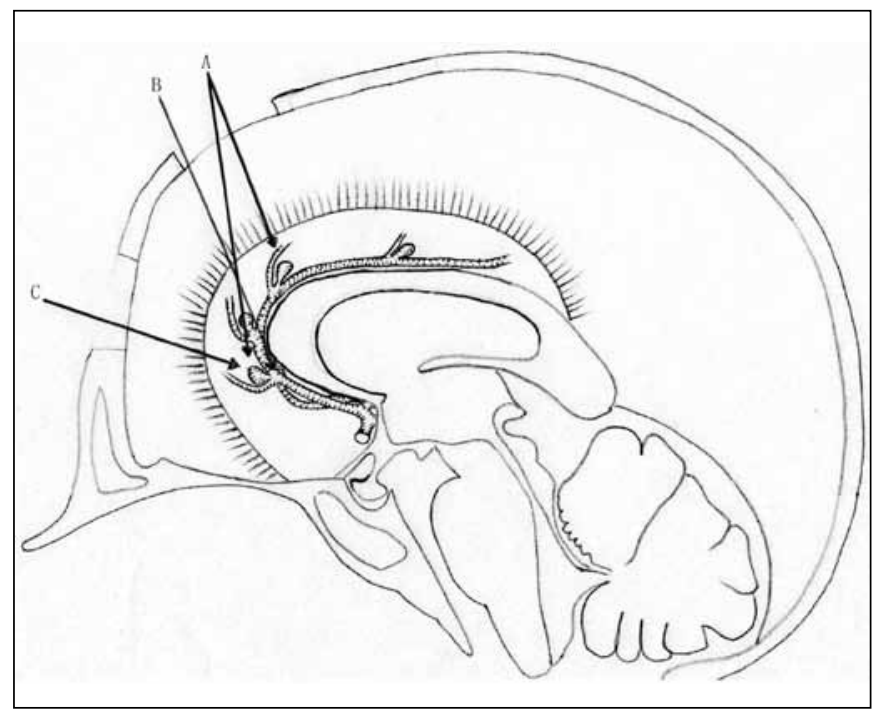

Figure 3: Schematic definition of the interhemispheric "keyhole" approach according to the anatomical location of A3As. Line A represented the interhemispheric "keyhole" approach for treatment of A3As; Line B meant adjusting the microscope to expose the A3As (including the inferior A3As) and proximal end of the parent artery during the operation; Line $\mathbf{C}$ meant the ideal and shortest path for treatment of the inferior A3As. 


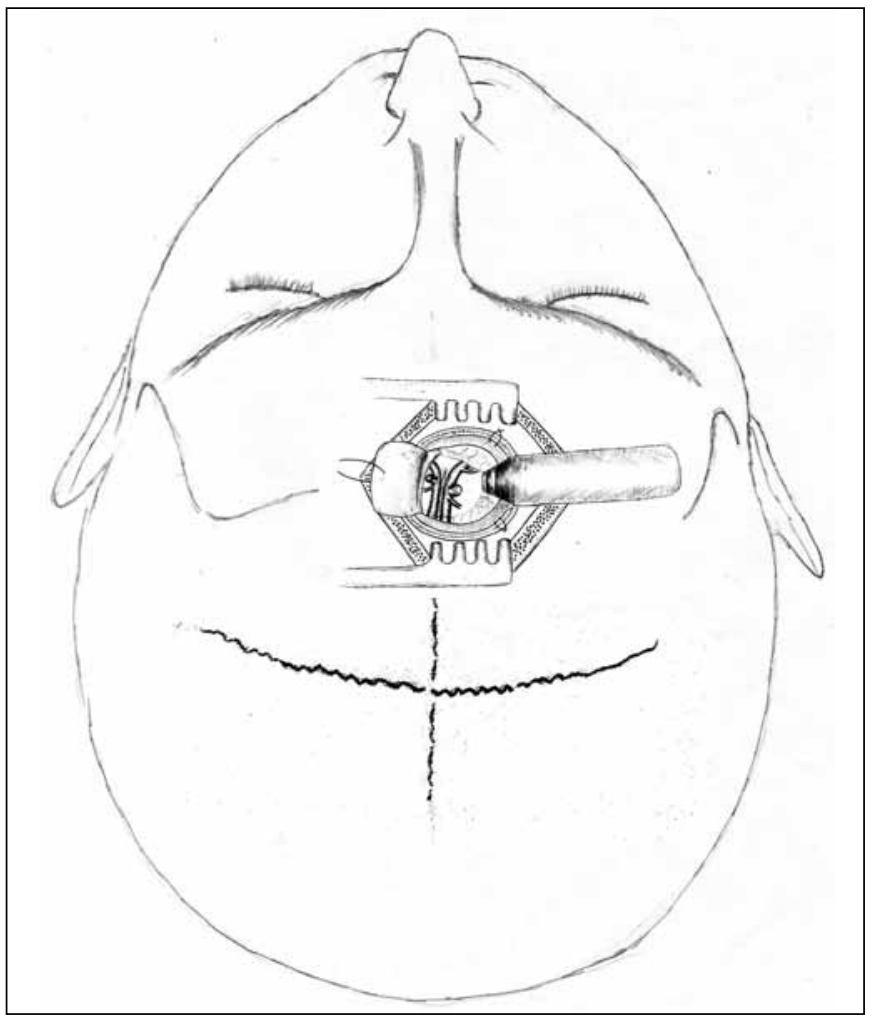

Figure 4: Illustration demonstrating the right-sided anterior interhemispheric keyhole approach suitable for treatment of A3As, regardless of its location at left or right side. operative angle and space. Ultimately, these aneurysms including the inferior A3As were successfully obliterated via anterior interhemispheric keyhole approach. And one patient with two aneurysms (a ruptured A3As and an unruptured aneurysm at the A1 segment of ACA) underwent single-stage clipping. There were no cerebral ischemia detected by SEP and/or MEP monitoring and no vascular stenosis detected by TCD during these aneurysm surgeries. Mean duration of surgery from skin incision to wound closure was $100 \mathrm{~min}$. with a range of $70 \mathrm{~min}$. to $135 \mathrm{~min}$. There were no severe interhemispheric keyhole approach related complications and no postoperative infections in the thirteen patients. Secondary intracranial haemorrhage and aneurysmal neck remnants were not detected by postoperative and follow-up images in those patients (Figure $6 \mathrm{~A}-\mathrm{H}$ ). One patient with severe cerebral vasospasm detected by preoperative CTA developed no aggravation of cerebral vasospasm; the other twelve patients also developed no severe cerebral vasospasm or neurological deficit. Mean length of hospital stay after surgery was 9.0 days (range 8 to 11 days). And the postoperative functional capacities of all these patients evaluated by GOS were normal six months later.

\section{DISCUSSION}

Keyhole microsurgery, as an important branch of modern minimally invasive neurosurgery, has been widely used in intracranial lesions surgery, and the "keyhole" effect is especially suitable for treatment of lesions deeply seated in the

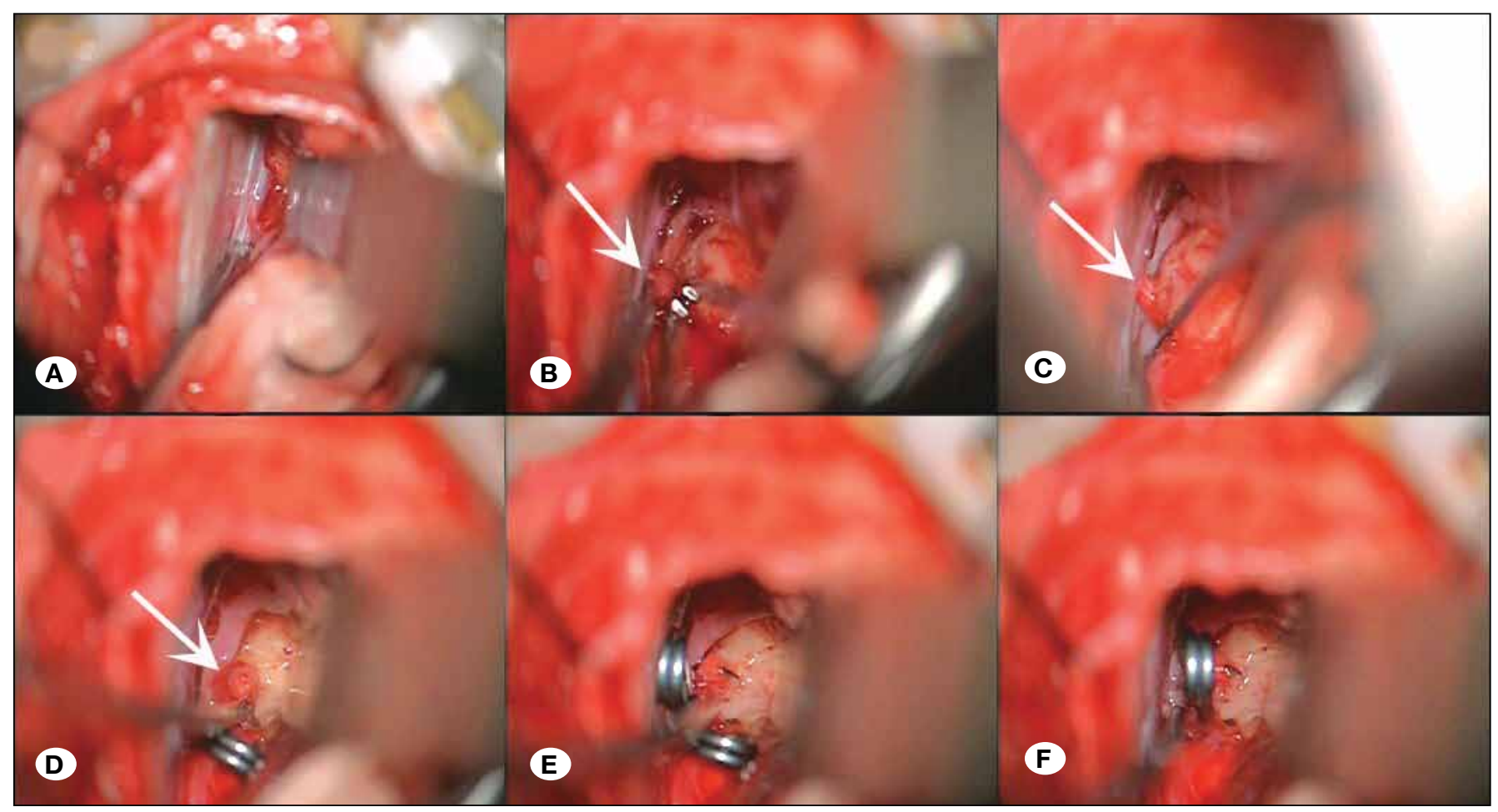

Figure 5: Illustration demonstrating the procedures of the A3As clipping. A) dissection of the interhemispheric fissure; B) exposure of the aneurysm(arrow); C) exposure of proximal end of the parent artery; D) temporary occlusion of parent artery and the unveiling of the aneurysm neck; E) aneurysm clipping; F) removal of the temporary clips. 

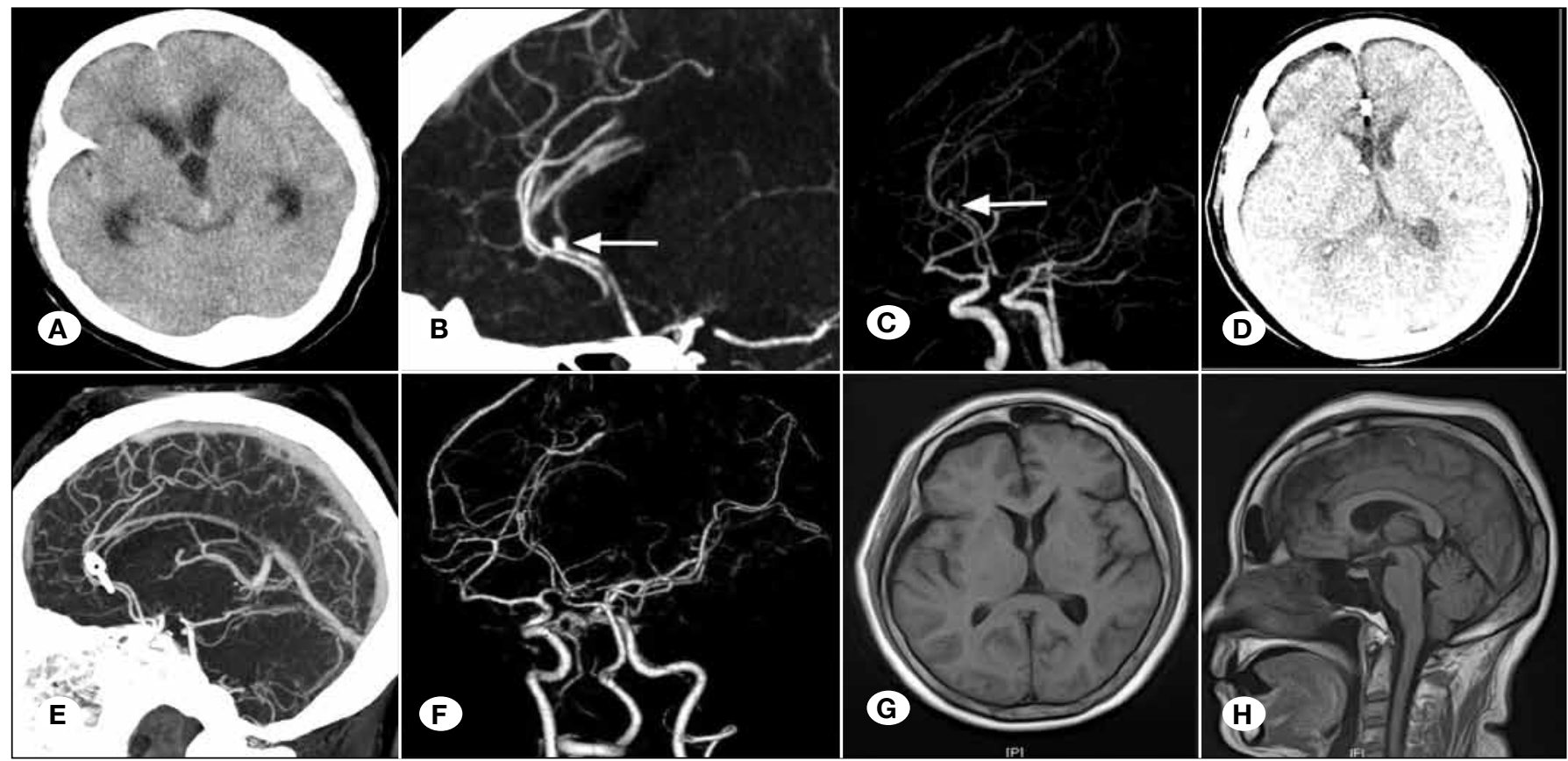

Figure 6: Ruptured anterior A3A (arrow) as seen on (A) preoperative CT, (B,C) preoperative CTA, (D) postoperative CT, (E,F) postoperative CTA, and $(\mathbf{G}, \mathbf{H})$ postoperative MRI.

brain (22). It is confirmed that the traditional interhemispheric approach could be utilized to manage the distal ACA aneurysms including the A3As. If the A3As are located at the A2-A3 junction, then a frontal, or a bifrontal, or a subfrontal approach may be the choice of treatment $(2,4,5,43)$. But none of them show minimally invasive advantages. Although the interhemispheric approach with the incision on the forehead wrinkle had been applied to the ACA aneurysm clipping successfully (8), the patients would feel forehead numbness postoperatively because of supraorbital nerve injury, and opening frontal sinus would increase the risk of infection (44). Therefore, the anterior interhemispheric keyhole approach with minimally invasive advantages was introduced into the treatment of the A3As. This article showed thirteen A3As and one $\mathrm{A} 1 \mathrm{~A}$ at our single institution were clipped successfully via anterior interhemispheric keyhole approach, and no severe keyhole approach related complications were detected. Here we show our preliminary experience:

1. The optimal location of the scalp incision and bone flap should be defined according to the anatomical location of aneurysm. And the exposure of the bone flap depends on the location of aneurysm in relation to the corpus callosum and intracerebral hemorrhages (24).

2. The procedures of aneurysm clipping through keyhole approach need elaborate design. And the anterior interhemispheric keyhole approach with a hairline incision across the midline depicted in this article is more suitable for the superior and anterior A3As (38) (Figures 2, 3). Although the bone flap is small, the sufficient intraoperative space in the anterior interhemispheric keyhole approach could be obtained through the drainage of the ventricular CSF and the adjustment of microscope, and the A3As (including the inferior A3As) and the proximal segment of parent arteries could be visible and the aneurysm clipping could be performed successfully.

3. It showed aesthetic advantages that the anterior interhemispheric keyhole approach with a hairline incision across the midline could prevent scarring on the forehead outside the hairline (Figures 2, 3). And patients did not feel forehead numbness because of no injury to the supraorbital nerve. In addition, it also helps avoid the risk of infection because of no opening to the frontal sinus after surgery.

4. Regardless of the locations of the A3As, the right-sided anterior interhemispheric keyhole approach could be chosen to avoid iatrogenic traumatizing to dominant hemisphere, and it is also convenient for a right-handed neurosurgeon (24) (Figure 4). However, the ipsilateral keyhole approach should be chosen as the optimal treatment of the A3As with hemorrhages in frontal lobe which should be removed during operations.

5. A miss is as good as a mile, and a small deviation of the incision or the bone flap in the keyhole approach could make the intraoperative aneurysms and the proximal end of their parent artery become invisible, and then operation will not proceed favorably. Therefore, the incision and the bone flap should also be precisely positioned during operation.

6. The dome of the aneurysm may be densely fixed on the pia layer of the cingulate gyrus, or it may even be within the gyrus (50). Therefore, the patients' images should be carefully evaluated to ascertain the dome projection and the neck configuration of the aneurysm before surgery, and frontal lobe should be retracted carefully and minimally to avoid intraoperative premature rupture of the aneurysms and iatrogenic traumatizing to frontal lobe during operation. 
7. The anterior interhemispheric keyhole approach here did not prolong duration of surgery dramatically. Our surgeries showed that the mean duration from scalp incision to wound closure was $100 \mathrm{~min}$.

8. If the aneurysms are difficult to locate intraoperatively due to variation of anatomical landmarks in their vicinity for the orientation inside the interhemispheric fissure, the neuronavigation will be helpful in finding the correct angle and approach to the aneurysm $(16,42)$. Although the brain shift occurs and makes the neuronavigation unreliable after CSF being drained from the ventricular system, it is known that the relative distance from the aneurysm to the genu of the corpus callosum and pericallosal artery is fixed, which is relatively less influenced by the brain shift. Therefore, the aneurysm would be found, after the genu of the corpus callosum or pericallosal artery was unveiled. In addition, the application of the assistive technologies such as intraoperative neurophysiological monitoring $(14)$ and $\operatorname{TCD}(1,12,29)$ make it possible to promptly adjust surgical procedures and minimize postoperative neurological deficits. It is worthy to note there exits a close relationship between reduced cerebral blood flow and reduction in SEP amplitude, and SEP monitoring is widely used in detecting cerebral ischemia. It is found that maintaining ischemia tolerance ratio (ITRs) less than $50 \%$ will avoid postoperative neurological deficits during operation, while an ITRs above $80 \%$ predicts them (14). Therefore, SEP warning criterion is also suitable for monitoring the ischemic changes to brain tissue supplied by the arteries of ACA. And there were no cerebral ischemia detected by intraoperative SEP and/or MEP monitoring in these patients.

9. It is recommended that external ventricular drainage is performed for removal of CSF to obtain more intraoperative space during ruptured aneurysm surgery via anterior interhemispheric keyhole approach, because the flow of CSF may be obstructed by subarachnoid clot after SAH, and the CSF cannot be easily removed from the subarachnoid space of interhemispheric fissure. If the A3A is unruptured, it also can be clipped successfully via this approach. However, the external ventricular drainage is not necessary for removal of CSF, which can be more easily removed from the interhemispheric fissure because subarachnoid space is unobstructed. In addition, the measure of ICP is also helpful for the adjustment of dehydrating agent. External drain of the CSF may reduce the risk of cerebral vasospasm in patients with SAH (37), reduce the dosage of mannitol and prevent mannitol-induced acute renal failure.

10. Because of the small bone window and the narrow space in the interhemispheric fissure, the anterior interhemispheric keyhole approach imposes high requirements upon micromanipulation and microscopic devices (8). In other words, excellent micromanipulation and advanced microscopic devices can make a perfect ending for anterior interhemispheric keyhole approach.

However, parts of the special challenges of the A3As listed by Yaşargil $(50)$ and Lehecka et al. $(24,25)$ were not encountered here. For example, we did not meet sclerotic wall and broadbase of the aneurysm which would make clip placement difficult. Therefore, further studies are necessary to evaluate the feasibility and benefits of the anterior interhemispheric keyhole approach for the management of A3As.

\section{- CONCLUSION}

The anterior interhemispheric keyhole approach combined with external ventricular drainage is a safe and effective craniotomy technique for treatment of the saccular A3As including the inferior A3As. And it prevents scarring on the forehead outside the hairline and shows its aesthetic and minimally invasive advantages, including minimal exposure and disruption of normal anatomy. The anterior interhemispheric keyhole approaches in the hands of experienced neurosurgeons with excellent and meticulous microsurgical techniques may be quick and invasive alternatives for treatment of A3As.

\section{ACKNOWLEDGMENT}

This study is sponsored by key clinical specialty discipline construction program of Fujian, P.R.C, the Young and Middle-aged Backbone Key Research Project of National Health and Family Planning Commission of Fujian Province (No. 2014-ZQV-ZD-14 to Liang-Hong Yu), major project of Fujian provincial department of science and technology (NO. 2014 YZ0003 and NO. 2014YZ01 to De-Zhi Kang) .

\section{REFERENCES}

1. Bailes JE, Tantuwaya LS, Fukushima T, Schurman GW, Davis D: Intraoperative microvascular Doppler sonography in aneurysm surgery. Neurosurgery 40:965-970; discussion 970962, 1997

2. Becker $\mathrm{DH}$, Newton $\mathrm{TH}$ : Distal anterior cerebral artery aneurysm. Neurosurgery 4:495-503, 1979

3. Chhabra R, Gupta SK, Mohindra S, Mukherjee K, Bapuraj R, Khandelwal N, Khosla VK: Distal anterior cerebral artery aneurysms: Bifrontal basal anterior interhemispheric approach. Surg Neurol 64:315-319; discussion 320, 2005

4. Chi JH, Lawton MT: Posterior interhemispheric approach: Surgical technique, application to vascular lesions, and benefits of gravity retraction. Neurosurgery 59:ONS41-49; discussion ONS41-49, 2006

5. Davidson L, Krieger MD, McComb JG: Posterior interhemispheric retrocallosal approach to pineal region and posterior fossa lesions in a pediatric population. J Neurosurg Pediatr 7:527-533, 2011

6. de Sousa AA, Dantas FL, de Cardoso GT, Costa BS: Distal anterior cerebral artery aneurysms. Surg Neurol 52:128-135; discussion 135-136, 1999

7. Fischer G, Stadie A, Reisch R, Hopf NJ, Fries G, BocherSchwarz $H$, van Lindert $E$, Ungersbock $K$, Knosp $E$, Oertel J, Perneczky A: The keyhole concept in aneurysm surgery: Results of the past 20 years. Neurosurgery 68:45-51; discussion 51, 2011

8. Fukushima T, Miyazaki S, Takusagawa $\mathrm{Y}$, Reichman M: Unilateral interhemispheric keyhole approach for anterior cerebral artery aneurysms. Acta Neurochir Suppl (Wien) 53:42-47, 1991 
9. Goryawala M, Yaylali I, Cabrerizo M, Vedala K, Adjouadi M: An effective intra-operative neurophysiological monitoring scheme for aneurysm clipping and spinal fusion surgeries. $J$ Neural Eng 9:026021, 2012

10. Hayashi N, Sato H, Akioka N, Kurosaki K, Hori S, Endo S: Unilateral anterior interhemispheric approach for anterior communicating artery aneurysms with horizontal head position-technical note. Neurol Med Chir (Tokyo) 51:160-163, 2011

11. Hernesniemi J, Tapaninaho A, Vapalahti M, Niskanen M, Kari A, Luukkonen M: Saccular aneurysms of the distal anterior cerebral artery and its branches. Neurosurgery 31:994-998; discussion 998-999, 1992

12. Hui PJ, Yan YH, Zhang SM, Wang Z, Yu ZQ, Zhou YX, Li XD, Cui G, Zhou D, Hui GZ, Lan Q: Intraoperative microvascular Doppler monitoring in intracranial aneurysm surgery. Chin Med J (Engl) 126:2424-2429, 2013

13. Inci S, Erbengi A, Ozgen T: Aneurysms of the distal anterior cerebral artery: Report of 14 cases and a review of the literature. Surg Neurol 50:130-139; discussion 139-140, 1998

14. Kang D, Yao P, Wu Z, Yu L: Ischemia changes and tolerance ratio of evoked potential monitoring in intracranial aneurysm surgery. Clin Neurol Neurosurg 115:552-556, 2013

15. Kawashima M, Matsushima T, Sasaki T: Surgical strategy for distal anterior cerebral artery aneurysms: Microsurgical anatomy. J Neurosurg 99:517-525, 2003

16. Kikuchi K, Watanabe K: Modified bifrontal interhemispheric approach to aneurysms of the anterior communicating artery with the use of a trephine craniotomy. A review of personal experience with 25 cases. Acta Neurochir (Wien) 125:127131,1993

17. Kim TS, Joo SP, Lee JK, Jung S, Kim JH, Kim SH, Kang SS, Yoon W: Neuronavigation-assisted surgery for distal anterior cerebral artery aneurysm. Minim Invasive Neurosurg 50:140144, 2007

18. Kim TS, Joo SP, Lee JK, Jung S, Kim JH, Kim SH, Kang SS, Yoon W: Neuronavigation-assisted surgery for distal anterior cerebral artery aneurysm. Minim Invasive Neurosurg 50:7781,2007

19. Kuwabara S, Ishikawa S, Andoh S, Matsumoto S, Sekimoto $\mathrm{H}$, Uemura Y, Yamane K, Takahashi M: Aneurysms of the distal anterior cerebral artery. Report of 18 cases and review of 191 reported cases. Neurol Med Chir (Tokyo) 24:580-590, 1984

20. Laitinen L, Snellman A: Aneurysms of the pericallosal artery: A study of 14 cases verified angiographically and treated mainly by direct surgical attack. J Neurosurg 17:447-458, 1960

21. Lan Q, Gong Z, Kang D, Zhang H, Qian Z, Chen J, Huang Q: Microsurgical experience with keyhole operations on intracranial aneurysms. Surg Neurol 66 Suppl 1:S2-9, 2006

22. Lan Q, Dong J, Huang Q: Minimally invasive keyhole approaches for removal of tumors of the third ventricle. Chin Med J (Engl) 119:1444-1450, 2006

23. Lehecka M, Lehto $H$, Niemela M, Juvela S, Dashti R, Koivisto T, Ronkainen A, Rinne J, Jaaskelainen JE, Hernesniemi JA: Distal anterior cerebral artery aneurysms: Treatment and outcome analysis of 501 patients. Neurosurgery 62:590-601; discussion 590-601, 2008
24. Lehecka M, Dashti R, Hernesniemi J, Niemela M, Koivisto T, Ronkainen A, Rinne J, Jaaskelainen J: Microneurosurgical management of aneurysms at A3 segment of anterior cerebral artery. Surg Neurol 70:135-151; discussion 152, 2008

25. Lehecka M, Dashti R, Hernesniemi J, Niemela M, Koivisto T, Ronkainen A, Rinne J, Jaaskelainen J: Microneurosurgical management of aneurysms at A4 and A5 segments and distal cortical branches of anterior cerebral artery. Surg Neurol 70:352-367; discussion 367, 2008

26. Ma Y, Lan $Q$ : An anatomic study of the occipital transtentorial keyhole approach. World Neurosurg 80:183-189, 2013

27. Maiuri F, Corriero G, D'Amico L, Simonetti L: Giant aneurysm of the pericallosal artery. Neurosurgery 26:703-706, 1990

28. Mann KS, Yue CP, Wong G: Aneurysms of the pericallosalcallosomarginal junction. Surg Neurol 21:261-266, 1984

29. Marchese E, Albanese A, Denaro L, Vignati A, Fernandez E, Maira G: Intraoperative microvascular Doppler in intracranial aneurysm surgery. Surg Neurol 63:336-342; discussion 342, 2005

30. Miyazawa N, Nukui H, Yagi S, Yamagata Z, Horikoshi T, Yagishita T, Sugita M: Statistical analysis of factors affecting the outcome of patients with ruptured distal anterior cerebral artery aneurysms. Acta Neurochir (Wien) 142:1241-1246, 2000

31. Mura J, Riquelme F, Cuevas JL, Luna F, Vizhnay P: Simplified azygos anterior cerebral bypass: Y-shaped superficial temporal artery interposition graft from A2 with double reimplantation of pericallosal arteries: Technical case report. Neurosurgery 72:onsE235-240; discussion ons240, 2013

32. Ohno K, Monma S, Suzuki R, Masaoka H, Matsushima Y, Hirakawa K: Saccular aneurysms of the distal anterior cerebral artery. Neurosurgery 27:907-912; discussion 912-913, 1990

33. Oka K, Rhoton AL Jr, Barry M, Rodriguez R: Microsurgical anatomy of the superficial veins of the cerebrum. Neurosurgery 17:711-748, 1985

34. Park J, Hamm IS: Anterior interhemispheric approach for distal anterior cerebral artery aneurysm surgery: Preoperative analysis of the venous anatomy can help to avoid venous infarction. Acta Neurochir (Wien) 146:973-977; discussion 977,2004

35. Perlmutter D, Rhoton AL Jr: Microsurgical anatomy of the distal anterior cerebral artery. J Neurosurg 49:204-228, 1978

36. Proust F, Toussaint $P$, Hannequin D, Rabenenoina $C$, Le Gars D, Freger P: Outcome in 43 patients with distal anterior cerebral artery aneurysms. Stroke 28:2405-2409, 1997

37. Ransom ER, Mocco J, Komotar RJ, Sahni D, Chang J, Hahn DK, Kim GH, Schmidt JM, Sciacca RR, Mayer SA, Connolly ES: External ventricular drainage response in poor grade aneurysmal subarachnoid hemorrhage: Effect on preoperative grading and prognosis. Neurocrit Care 6:174-180, 2007

38. Rodriguez-Hernandez A, Zador Z, Rodriguez-Mena R, Lawton MT: Distal aneurysms of intracranial arteries: Application of numerical nomenclature, predilection for cerebellar arteries, and results of surgical management. World Neurosurg 80:103112,2013

39. Sindou M, Pelissou-Guyotat I, Mertens P, Keravel Y, Athayde AA: Pericallosal aneurysms. Surg Neurol 30:434-440, 1988 
40. Steiger HJ, Schmid-Elsaesser R, Stummer W, Uhl E: Transorbital keyhole approach to anterior communicating artery aneurysms. Neurosurgery 48:347-351; discussion 351352, 2001

41. Steven DA, Lownie SP, Ferguson GG: Aneurysms of the distal anterior cerebral artery: Results in 59 consecutively managed patients. Neurosurgery 60:227-233; discussion 234, 2007

42. Suzuki J, Mizoi K, Yoshimoto T: Bifrontal interhemispheric approach to aneurysms of the anterior communicating artery. J Neurosurg 64:183-190, 1986

43. Suzuki S, Kurata A, Yamada M, Iwamoto K, Nakahara K, Sato K, Niki J, Sasaki M, Kitahara T, Fujii K, Kan S: Outcomes analysis of ruptured distal anterior cerebral artery aneurysms treated by endosaccular embolization and surgical clipping. Interv Neuroradiol 17:49-57, 2011

44. van Lindert E, Perneczky A, Fries G, Pierangeli E: The supraorbital keyhole approach to supratentorial aneurysms: Concept and technique. Surg Neurol 49:481-489; discussion 489-490, 1998
45. Weigang E, Hartert M, Sircar R, P VS, Pitzer K, Genstorfer $\mathrm{J}$, Zentner J, Beyersdorf F: Setup of neurophysiological monitoring with tcMEP/SSEP during thoracoabdominal aneurysm repair. Thorac Cardiovasc Surg 53:28-32, 2005

46. Wilson G, Riggs HE, Rupp C: The pathologic anatomy of ruptured cerebral aneurysms. J Neurosurg 11:128-134, 1954

47. Wilson DH: Limited exposure in cerebral surgery. Technical note. J Neurosurg 34:102-106, 1971

48. Wisoff JH, Flamm ES: Aneurysms of the distal anterior cerebral artery and associated vascular anomalies. Neurosurgery 20:735-741, 1987

49. Yasargil MG, Carter LP: Saccular aneurysms of the distal anterior cerebral artery. J Neurosurg 40:218-223, 1974

50. Yaşargil MG: Distal anterior cerebral artery aneurysms (pericallosal artery aneurysms). Microneurosurgery 2:224231, 1984

51. Yoshimoto T, Uchida K, Suzuki J: Surgical treatment of distal anterior cerebral artery aneurysms. J Neurosurg 50:40-44, 1979 